\title{
ESTIMATION OF THE FREQUENCY OF NIGHTTIME HYPOGLYCEMIC REACTION CASES IN DIABETES MELLITUS OF THE TYPE 1
}

Authors E. Makhlina, Y. Navmenova*, T. Mokhort**

SI Republican Research Centre for Radiation Medicine and Human Ecology,

Gomel State Medical University*, Belarusian State Medical University**

OBJECTIVES

To estimate the frequency of nighttime hypoglycemic reaction cases in daily monitoring of the glucose in interstitial fluid under the conditions of DM 1.

\section{METHODS}

\begin{tabular}{|c|c|c|c|}
\hline & $1^{\text {st }}$ group $(n=50)$ & $2^{\text {nd }}$ group ( $n=63$ ) & $\mathbf{p}$ \\
\hline Age, years & $29,49[24,05 ; 36,18]$ & $27,83[21,13 ; 34,94]$ & 0,346 \\
\hline Duration of DM 1 , years & $9,07[4,23 ; 13,53]$ & $7,18[2,78 ; 13,62]$ & 0,302 \\
\hline $\mathrm{HbA}_{1 \mathrm{C}}, \%$ & $8,20[7,30 ; 9,40]$ & $9,70[8,40 ; 11,20]$ & $<0,001$ \\
\hline Body mass index, $\mathrm{kg} / \mathrm{m} 2$ & $23,66[21,97 ; 25,82]$ & $23,42[21,45 ; 27,34]$ & 0,930 \\
\hline Day dose of insulin, IU/day & $0,72[0,60 ; 0,87]$ & $0,72[0,56 ; 0,98]$ & 0,476 \\
\hline
\end{tabular}

The frequency of night hypoglycemic reaction cases in the group 1 according to gender
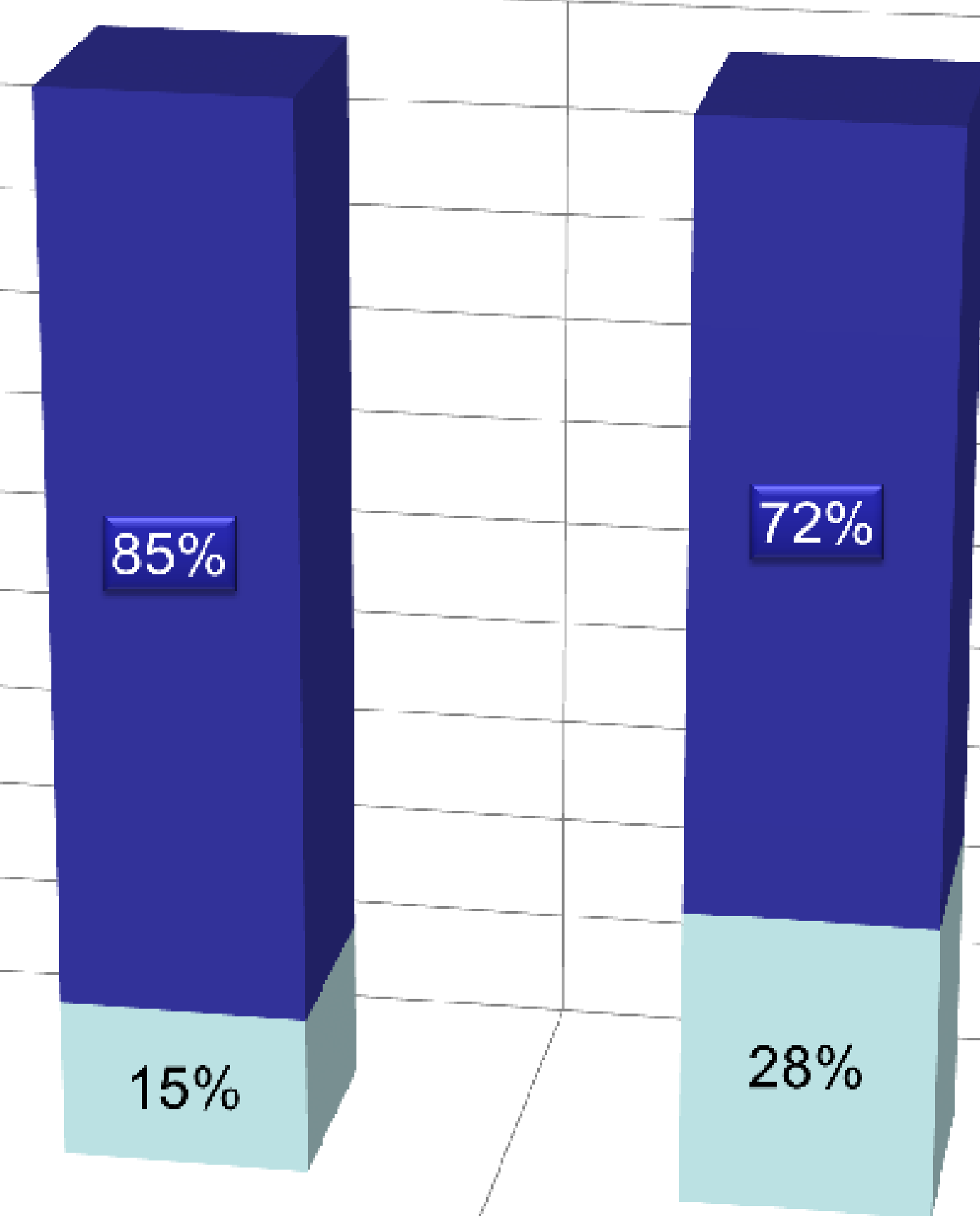
- No nighttime hypoglycemic episodes
The presence of nighttime hypoglycemic episodes

The study of daily glucose dynamics was conducted with the use of the continuous glucose monitoring system made by the company Medtronik MINIMED, USA. The study included 113 patients with DM 1. Patients ware divided into 2 groups: group 1 with nighttime hypoglycemic reaction cases $(n=50)$, and group 2 without nighttime hypoglycemic reaction cases $(n=63)$.

\section{RESULTS}

The age of the patients in the group 1 was $29,49[24,05$; $36,18]$ years, in the group 2 it was $27,83[21,13 ; 34,94]$ years $(\mathrm{p}>0,05)$. The period of the DM 1 in the group 1 was $9,07[4,23 ; 13,53]$, in the group 2 it was $7,18[2,78$; $13,62]$ years $(p>0,05)$. The level of $\mathrm{HbAlc}$ in the group 1 was $8,20[7,30 ; 9,40] \%$, in the group 2 it was $9,70[8,40$; $11,20] \%,(p<0,001)$. BMI in the group 1 was 23,66 $[21,97 ; 25,82] \mathrm{kg} / \mathrm{m} 2$, in the group 2 it was $23,42[21,45$; $27,34] \mathrm{kg} / \mathrm{m} 2(\mathrm{p}>0,05)$. The daily dose of insulin in the group 1 was $0,72[0,60 ; 0,87] \mathrm{IU} / \mathrm{\kappa}$, in the group 2 it was $0,72[0,56 ; 0,98] \mathrm{IU} /$ кг $(\mathrm{p}>0,05)$. The frequency of night hypoglycemic reaction cases in the group 1 was $15 \%$ in males and $28 \%$ in females $(p>0,05)$.

In the group 1 the level of glucose in interstitial fluid 1 hour before the dinner was $8,30[5,70 ; 10,00] \mathrm{mmol} / \mathrm{l}$, it was $10,75[8,45 ; 14,25] \mathrm{mmol} / 1$ in the group 2 . In 3 hours after the dinner the level of glucose in interstitial fluid in group 1 was $8,05[5,80 ; 9,90] \mathrm{mmol} / \mathrm{l}$, it was $10,90[8,60 ; 13,70] \mathrm{mmol} / \mathrm{l}(\mathrm{p}<0,001)$ in the group 2.Between 23:00 and 03:00 the level of glucose in interstitial fluid in the group 1 was $7,80[5,50 ; 10,60]$ $\mathrm{mmol} / \mathrm{l}$, it was $10,50[8,80 ; 13,40] \mathrm{mmol} / \mathrm{l},(\mathrm{p}<0,001)$ in the group 2. Between 03:00 and 06:00 the level of glucose in interstitial fluid in group 1 was $8,20[6,10$; $11,10] \mathrm{mmol} / \mathrm{l}$, it was $10,80 \quad[8,70 ; 13,30] \mathrm{mmol} / 1$ $(\mathrm{p}<0,001)$ in the group 2 .

\section{CONCLUSIONS}

-The frequency of nighttime hypoglycemic reaction cases doesn't depend on sex, age, period of DM 1, daily dose of injected insulin.

-The risk of night hypoglycemic reactions is higher in patients with the lower risk index of hypoglycemia that coincides with the minimum value of glycaemia at night and glycosylated hemoglobin. 